\title{
PRÁTICAS LETRADAS, TECNOLOGIAS E TERRITÓRIOS: TRANSGREDINDO RELAÇÕES DE PODER
}

Literacy Practices, Technologies and Territories: Transgressing Power Relations

\author{
Luiz Henrique MAGNANI (UFVJM) ${ }^{1}$ \\ Carlos Henrique Silva de CASTRO (UFJVM) ${ }^{2}$
}

\begin{abstract}
RESUMO: No presente trabalho, busca-se refletir sobre o uso de tecnologias e o papel destas em práticas letradas ligadas a diferentes contextos rurais. Entende-se que atividades educativas que envolvam a questão da linguagem nesses meios devem levar em conta a realidade de usos de tecnologia presente. Percebe-se uma tendência de a discussão sobre tecnologias e práticas relacionadas em ações educativas ser mais invisibilizada quando diz respeito a territórios não-urbanos, uma vez que as universidades e seus pesquisadores se localizam majoritariamente nos espaços dos centros urbanos, a partir de onde costumam operar. Em contrapartida, parte da reflexão aqui proposta tem como base experiências empíricas vivenciadas pelos autores em contextos sociais e universitários concretos articulados com espaços rurais, nos quais sujeitos do campo se fazem presentes. A partir disso, busca-se contribuir com tal discussão tendo por base práticas educativas que promovam a equidade e viabilizem as condições para grupos do campo e rurais representarem-se. Esse deslocamento, espera-se, pode levar a reduzir ou dispensar a intermediação da mídia legitimada ou de discursos majoritariamente urbanos e exógenos a respeito do campo, democratizando o acesso ao capital cultural contemporâneo e legitimando práticas e tecnologias já existentes nesse contexto ou potencialmente benéficas às demandas educativas ali emergentes.
\end{abstract}

PALAVRAS-CHAVE: práticas letradas; tecnologias; territórios; educação do campo; relações de poder.

ABSTRACT: We seek to reflect on the use of technologies and their role in literate practices linked to different rural contexts. We understand that educational activities that involve the issue of language in these contexts should consider their reality of uses of the technologies. There is a tendency for the discussion about technologies and practices related to educational actions to be more invisible when it concerns to non-urban territories, since universities and their researchers are located mainly in

\footnotetext{
${ }^{1}$ Professor na Universidade Federal dos Vales do Jequitinhonha e Mucuri (UFVJM). Doutor em Letras pela Universidade de São Paulo (USP) no Programa de Pós-Graduação em Estudos Linguísticos e Literários em Inglês. henriquemagnani@gmail.com

${ }^{2}$ Professor na Universidade Federal dos Vales do Jequitinhonha e Mucuri (UFVJM). Doutor em Linguística Aplicada pela Universidade de Minas Gerais (UFMG). ccastrobr@gmail.com
} 


\section{Dossiê Especial FICLLA}

REVISTA X, Curitiba, volume 14, n.5,p. 56-81, 2019

the spaces of the urban centers, from where they usually operate. On the other hand, part of the reflection proposed here is based on empirical practices experienced by the authors in concrete social and university contexts articulated with rural spaces and subjects. We seek to contribute to such discussion based on educational practices that promote equity and enable the conditions for rural groups to represent themselves. This shift, as we hope, may lead to reducing or dispensing the mediation of legitimized media or urban and exogenous discourses about the rural areas, democratizing access to contemporary cultural capital, and legitimizing practices and technologies existing in that context or potentially beneficial to their emerging educational demands.

KEYWORDS: literacy practices; technologies; territories; rural education; power relations.

\section{APRESENTAÇÃO}

A reflexão aqui proposta tem como base uma Roda de Conversa com pauta similar realizada no FICLLA que envolveu parte da comunidade acadêmica presente no evento. Uma das questões centrais deste artigo é procurar visibilizar o fato de que as tecnologias e seus usos emergem, disseminam-se e consolidam-se de modos assimétricos nas sociedades e nos diferentes territórios. E que essa constatação mais ampla, inclusive, leva a desdobramentos em relação ao modo como pensamos diversas esferas de organização social, envolvendo áreas como políticas públicas e educação, por exemplo.

Sabe-se que a escolha e a organização de procedimentos, tecnologias e conteúdos podem influenciar no papel político da escola para seus estudantes e determinar o alcance de ressonância das vozes da comunidade escolar tanto em sua luta em prol das transformações sociais quanto para sua maior participação política e representação de sentidos. Assim, problematizações teóricas e propostas pedagógicas que busquem trabalhar com essa pauta da tecnologia e seus usos necessitam levar em consideração esse dado. Isso, em especial, quando o território em questão difere qualitativamente daquele no qual as teorias utilizadas são produzidas. Um exemplo disso seriam práticas letradas ligadas a novas tecnologias e ao meio digital ocorridas em contextos não urbanos, um dos objetos de atenção do presente trabalho. Ressalta-se, ainda, que essa lógica também abarca outras tecnologias, como a própria escrita. 


\section{Dossiê Especial FICLLA}

REVISTA X, Curitiba, volume 14, n.5,p.56-81, 2019

$\mathrm{Na}$ seção a seguir, procuramos nos aprofundar em tais debates a partir de um conjunto inicial de reflexões, envolvendo o próprio fazer acadêmico enquanto atividade que ocorre dentro de condições e contextos específicos, além de refletir como essa questão se desdobra em reflexões e práticas que envolvam letramento, linguagens e tecnologias em contextos educativos dissonantes dos previstos ou relatados em alguns estudos teóricos de alcance por vezes mais abrangente na comunidade acadêmica. Entende-se que essa pode ser uma contextualização útil para as seções seguintes.

A partir disso, traz-se um conjunto de relatos e dados a respeito de atividades educativas que envolvem práticas letradas e uso de tecnologias no âmbito do curso de Licenciatura em Educação do Campo (LEC) da Universidade Federal dos Vales do Jequitinhonha e Mucuri (UFVJM). Objetiva-se com isso ressaltar alguns contextos, territórios e redes que articulam espaços urbanos e não urbanos e que fogem, muitas vezes, de locais de análise já privilegiados por outros estudos sobre linguagem e tecnologias. Por fim, busca-se elaborar algumas considerações finais a respeito da problematização apresentada.

\section{REFLEXÕES INICIAIS}

Observa-se que, no processo histórico do fazer acadêmico, há uma tendência de se hierarquizar - em termos de pertinência científica, validade e importância - procedimentos, metodologias, análises, formas e resultados obtidos. Dentro disso, ainda é influente o imaginário que evoca a necessidade de um olhar mais 'universal" ou um modelo explicativo mais amplo e eficiente para dada questão ou tema, o qual se sobreponha aos demais por méritos técnicos ou formais. Em um sentido mais amplo, pode-se mencionar o contraste entre saberes considerados científicos e não científicos, estes, costumeiramente deslegitimados pelos primeiros (SANTOS, 2005; 2008; 2018). Um olhar crítico a essa postura pode nos lembrar que a própria ciência moderna operou a partir de uma lógica na qual, conforme Santos (2008, p. 15), “passou a responder exclusivamente aos problemas postos por ela.".

Reitera-se, também, que, dentro da academia, algumas áreas possuem mais prestígio que outras (RAJAGOPALAN, 2003; FIORIN, 2012). Dentro das áreas, ainda, as vertentes 


\section{Dossiê Especial FICLLA}

REVISTA X, Curitiba, volume 14, n.5,p.56-81, 2019

teóricas também se distribuem desigualmente. E, ainda, em uma mesma vertente, há uma assimetria que envolve quais acadêmicos e quais instituições são mais autorizadas ou menos para produzir conteúdos legítimos. A lógica que parece prevalecer, portanto, é a de uma organização vertical do conhecimento, a qual permanece pressupondo uma régua mais ou menos universal. Instituições, acadêmicos, áreas, vertentes de mais prestígio ocupam degraus mais altos dessa pirâmide e, portanto, produções a eles relativas devem ser divulgadas e consumidas por um maior número de sujeitos. Em degraus inferiores, estariam relatos, reflexões, produções tidas como de interesse mais restrito, mais 'locais'.

Isso, no entanto, não apaga o modo como o fazer acadêmico se dá concretamente nas salas de aulas, nos espaços de pesquisa, nos congressos, nos grupos de estudo, em suma, na lógica cotidiana da vida acadêmica. Nota-se, vale insistir no argumento, que a maneira como a estrutura do fazer acadêmico, dependente de sujeitos e instituições com diferentes status, permanece priorizando a circulação e o consumo de experiências específicas - normalmente produzidas em contextos de maior prestígio e com maiores condições de fazerem circular suas próprias ideias - como escopo reflexivo. Ou seja, a lógica da hierarquização tem as mais diversas dimensões.

Dentro da área das linguagens, por exemplo, parte dessa pressão costuma vir da própria busca histórica da Linguística se legitimar como ciência (RAJAGOPALAN 2003). É provável que essa tendência venha como percepção interna e histórica de que, dentro do 'mercado acadêmico', a área de Letras e de estudos linguísticos vale menos que outras, mais consagradas (FIORIN, 2012). Como pontua Rajagopalan, desde o momento inaugural da área

\footnotetext{
um certo espírito daquilo que se chama 'cientismo' tem varrido a disciplina. Trata-se de um desejo de fazer da linguística uma ciência a qualquer custo, mesmo que isso implique ter que abrir mão de qualquer preocupação de ordem prática [...]. Cabe lembrar que um dos pilares do cientismo é a tese de que as chamadas 'ciências sociais' só se justificam como ciências na medida em que se submetem ao rigor científico próprio das ciências exatas, estas sim, tidas como ciências na plenitude linguística da palavra (RAJAGOPALAN, 2003, p. 43).
}

Esse modo de operar no contexto da área da linguagem, apesar de canônico e muito influente, não é único nem monolítico, resvalando em resistências e tensionamentos internos. Tais tensionamentos podem, inclusive, gerar distanciamentos e dissidências, 


\section{Dossiê Especial FICLLA}

REVISTA X, Curitiba, volume 14, n.5,p.56-81, 2019

fazendo emergir novas disciplinas ou áreas de concentração, em uma dinâmica que não é nova e já foi objeto de reflexões em contexto acadêmico (KUHN, 1975). Assim ocorreu com a própria Linguística Aplicada, área na qual os autores do presente trabalho se situam. Conforme Signorini (1998) nos permite recordar, em contraste a uma forma mais consolidada historicamente de se fazer linguística, há, na Linguística Aplicada, uma busca investigativa voltada ao acontecimento, a qual se faz metodologicamente tão rigorosa quanto possível, mas com a nitidez de que essa atividade não necessariamente vai caber nos moldes teóricos e na estrutura preestabelecida de uma ciência que se pressupõe universal ou universalizante.

Quando se vai para um recorte mais específico, como os debates sobre letramento e tecnologias, não é diferente. Parece haver, ainda, a tendência, de valorizar em especial contribuições estrangeiras, normalmente vindas de países ocidentais mais prestigiados. Assim é o caso da influência de perspectivas como a dos 'multiletramentos', disseminada pelo New London Group e a dos 'Novos Estudos do Letramento', proposta por Brian Street. Nas reflexões sobre novas mídias e tecnologias os exemplos também são muitos, desde a influência de reflexões sobre a 'cultura da convergência' (JENKINS, 2008); a ideia de 'cibercultura' (LEVY, 1999); a ideia de uma 'cultura da simulação' (TURKLE, 1995), o videogame como exemplo ou inspiração para boas práticas educativas (GEE, 2003) entre tantos outros.

De um lado, parece compreensível que tenham maior alcance e influência reflexões sobre novas tecnologias quando produzidas em locais que, muitas vezes não apenas são mais prestigiados no mercado das trocas acadêmicas, mas também coincidem como local em que tais tecnologias surgem ou são desenvolvidas. Na prática, de outro lado, não se pode ignorar que o discurso científico também é gênero e forma de representação dependentes de suas condições de produção (NUNES, 2005). Toda produção acadêmica, por ser situada, visibiliza aspectos pertinentes às suas condições de produção. Tais aspectos, no entanto, não são, necessariamente, representativos de outros contextos e territórios.

'Esquecer' que a produção científica também é um gênero discursivo - localizado no tempo e no espaço, produzido por sujeitos e coletivos sociais - induz a uma impressão 
de desterritorialização da ciência. $\mathrm{O}$ cientista poderia produzir suas reflexões em qualquer local ou território pois, caso suas constatações sejam realmente objetivas, elas independerão de fatores contextuais. No entanto, estudos que talvez sejam extremamente relevantes para um território ou localidade podem, por outro lado, simplesmente não terem pertinência em outras situações. Outro problema concreto desse tipo de lógica é que isso pode criar confusões e apagamentos a respeito das razões pelas quais certos conhecimentos são produzidos ou não. Em termos bem práticos, por exemplo, é de se prever que instituições que possuam maior apoio financeiro tenham mais condições de produzir e publicizar trabalhos acadêmicos, os quais podem tematizar aspectos e debates que, pertinentes em seus contextos de produção, não possuem a mesma ressonância em outros locais com menos incentivo à pesquisa.

Essa reflexão pode ganhar maior nitidez e profundidade a partir de exemplos. Para tanto, apresenta-se de modo muito breve e sintético, duas entre muitas possibilidades de ilustrar o ponto em questão. Partindo de um contexto no qual a escola não se mostra atrativa aos estudantes, Gee (2003) pondera o quão interessante seria se, a exemplo de como jogadores se engajam e aprendem com videogames, estudantes desejassem colocar o mesmo tanto de tempo e esforço em resolver problemas desafiadores no contexto escolar. Para tanto, busca analisar alguns princípios presentes nos videogames que, assume, poderiam ajudar a pensar melhores princípios de aprendizados para escolas. Esse trabalho influenciou grande parte dos estudiosos que procuraram relacionar videogames e práticas letradas em sala de aula. Em uma leitura a respeito da proposta do autor, Hung (2009) problematiza alguns pontos, entre os quais a própria representatividade da coleta de dados empreendida. Hung (2009) aponta que as visões de Gee sobre videogames

\footnotetext{
(...) tendem a se basear mais em experiências pessoais do que em estudos empíricos. Não fica claro se o modo de aprender que ele descreve é universalmente válido para todos os videogames e todos os jogadores. Nem todos os jogadores jogam os mesmos videogames, nem todos os videogames se mostram bem-sucedidos, e nem todos os videogames de sucesso são apreciados por todos seus jogadores (HUNG, 2009, p. 21-22).
}

Quais serão, portanto, os limites do alcance explicativo de uma perspectiva ambiciosa como a de Gee (2003), que busca refletir sobre princípios de aprendizado presentes ou possíveis na escola a partir da prática interativa com videogames? Qual escola, 
qual sujeito, qual videogame, qual sociedade, qual acesso à tecnologia Gee tem em mente quando propõe suas reflexões?

Um segundo exemplo para a presente argumentação pode ser trazido a partir da obra de Jenkins (2008). Em uma análise da sociedade e do uso de mídias, o autor aponta para a emergência daquilo que alcunha como 'cultura da convergência', “onde as velhas e as novas mídias colidem, onde a mídia corporativa e mídia alternativa se cruzam, onde o poder do produtor de mídia e o poder do consumidor interagem de maneiras imprevisíveis" (JENKINS, 2008, p. 27). Como estratégia para corroborar com essa perspectiva e explorála em detalhes e desdobramentos, o autor aborda algumas práticas que vinculam tecnologias, sujeitos, mídias - tal como a possibilidade de pessoas ao redor do mundo participarem colaborativamente de um fórum a respeito de um programa televisivo ou a possibilidade de uma narrativa demandar interação nas mais diversas mídias, passando por filmes em cinema, animações, videogames, entre outros. Mais de dez anos após sua publicação, muitas práticas e formas de interagir com a tecnologia descritas no livro não são comuns ou, por vezes, possíveis a muitos sujeitos de comunidades do campo brasileiros. Isso, seja por questões de acessos às estruturas (computadores, banda larga, consoles de videogame, acesso a cinemas físicos), domínio de práticas letradas necessárias às interações ou, mesmo, domínio da língua utilizada em muitas dessas práticas - o inglês. Outras práticas letradas e usos de tecnologia, ainda, emergiram sem ter sido previstas pelo autor, que é, claro, o esperado de ocorrer ${ }^{3}$.

A esse respeito, é importante pontuar que, longe de descartar os insights de Gee (2003) e Jenkins (2008), bem como as contribuições de outros(as) tantos(as) autores(as), o presente trabalho procura chamar a atenção para o fato de que há elementos a respeito de práticas letradas e usos de tecnologia que demandam maior conhecimento empírico e entendimento das vivências concretas das comunidades nas quais elas cotidianamente ocorrem. Sem isso, corre-se o risco de se tentar encaixar ou aplicar diretamente, de modo forçado ou reducionista, categorias e perspectivas teóricas que foram desenvolvidas em

\footnotetext{
${ }^{3}$ Isso não quer dizer que haveria qualquer desejo ou responsabilidade de o trabalho do autor ter essa abrangência. Ou seja, é necessário estar nítido que o presente apontamento constata apenas a impossibilidade de qualquer obra ser representativa de todos os variados contextos de usos e práticas com novas mídias.
} 
condições de produção diferentes e, também, particulares. Essa preocupação se alinha com o argumento presente em Magnani (2011) de que os estudos sobre práticas letradas, ainda que vinculados à área da educação, precisam dar um passo além do contexto estrito da sala da aula - ou, quando muito, dos limites da escola. As práticas letradas concretas e cotidianas que estão na vida dos sujeitos são um componente importante no entendimento do tipo de ações educativas que um professor poderia priorizar. Esse tipo de percepção não é possível de se obter, no entanto, se os estudos sobre letramento, tecnologias e ensino estiverem restritos a cenários específicos - como a escola urbana - ou produzidos em sociedades com situações muito diferentes a respeito do uso de tecnologia, fontes comuns de estudos influentes sobre o tema.

Em uma escala menor, por exemplo, não é difícil ocorrer uma situação análoga ao se pensar nas diversas práticas letradas e usos de tecnologia possíveis nas diferentes comunidades existentes no Brasil. Há um nítido amadurecimento no âmbito acadêmico nacional a respeito de questões de linguagem, letramentos, tecnologias, novas mídias e assuntos correlatos; tais como: hipertextualidade, multimodalidade, interatividade, entre outros. Debates deste teor têm emergido sejam em monografias diversas, como dissertações, teses, artigos e livros seja em coletâneas publicadas envolvendo, em especial, acadêmicos em atividade no contexto das universidades brasileiras ${ }^{4}$.

Há, por sua vez, uma maior dificuldade de se localizar trabalhos de alcance nacional que explicitem relação com alguma particularidade territorial ou identitária não-urbana ${ }^{5}$. Essa constatação não é uma crítica a autores que, inserido em seus contextos de produção e com as demandas e interesses de trabalho pautadas pelos seus cotidianos, possuem sua agenda própria. O ponto é que, em sua grande maioria, as universidades públicas do Brasil, sabidamente as maiores produtoras de conhecimento científico do país, localizam-se em centros urbanos. Assim, ainda que possam absorver sujeitos oriundos de comunidades

\footnotetext{
${ }^{4}$ Ver, a esse respeito, trabalhos como (BUZATO, 2007; BRAGA, 2013; BRAGA, 2015; JESUS E MACIEL, 2015; ZACCHI e WIELEWICKI, 2015; ARAÚJO e LEFFA, 2016; TAKAKI e MACIEL, 2017; TAKAKI e MONTE MÓR, 2017). Os exemplos aqui citados não esgotam o panorama das produções sobre linguagem e novas tecnologias no país e nem pretendem fazê-lo.

${ }^{5}$ Salienta-se, a esse respeito, o trabalho realizado por Zacchi (2006) que analisa aspectos de letramento e identidade em produções textuais do movimento MST.
} 
rurais, seu funcionamento, seu local de produção, a realidade cotidiana empírica, os índices de produtividade aos quais estão sujeitos, entre outros fatores, tendem a atravessar a produção científica realizada, reiterando a atenção para contextos urbanos. Entre outros fatores, essa condição pode ajudar a explicar um descompasso entre variadas reflexões acadêmicas ou propostas pedagógicas que partam do uso (ou de certos usos) de certas tecnologias e estruturas - presença de banda larga, acesso a certos jogos digitais, uso de certos softwares - e as realidades de muitas escolas e comunidades do campo. Diante do que foi exposto, há sempre o perigo de se invisibilizar práticas e situações que, por razões variadas que incluem a própria assimetria entre as instituições brasileiras, acabam tendo menos condições de ser tema ou objeto de estudo. A questão das práticas sociais de linguagens ligadas às novas tecnologias em contextos não-urbanos parece ser um desses pontos.

Emerge, em decorrência, a questão de como pensar e produzir conhecimento acadêmico sobre tecnologias e letramentos com a preocupação de que tais conhecimentos sejam relevantes e condizentes em relação às demandas e vivências de diversas realidades não-urbanas ou menos urbanizadas existentes no Brasil e ainda pouco contempladas como tema investigativo. Isso tudo, claro, necessariamente de modo interligado com o cenário mais amplo no qual essa realidade está inserida, com suas pautas e seus pressupostos. Uma realidade, portanto, necessariamente híbrida. Porém, argumenta-se, dentro dos elementos que contribuem para esse hibridismo, as particularidades empíricas da localidade parecem ocupar menos a atenção das reflexões teóricas sobre o tema do que a onipresença das novas formas de interagir e se comunicar relacionadas a tecnologias atuais de comunicação, ao meio digital e à internet. Talvez seja interessante que novas pesquisas passem a levar em consideração essa percepção.

Nesse sentido, parece que o acréscimo da ideia de 'territorialidade' como um componente das reflexões sobre linguagem, letramentos e tecnologia tem grande potencial de contribuir a situação percebida. Longe de procurar regras universais a respeito do tema, ou novos paradigmas que se imponham aos demais, fazem-se necessários estudos que ampliem o mapeamento de práticas possíveis e visíveis ao longo dos diferentes contextos e territórios. Grosso modo, o entendimento desses termos no contexto do presente artigo 
alinha-se com a perspectiva de Haesbaert (2004) e de Costa e Carvalho (2012). O primeiro explica as conotações significativas do termo:

\begin{abstract}
Desde a origem, o território nasce com uma dupla conotação, material e simbólica, pois etimologicamente aparece tão próximo de terra-territorium quanto de terreo-territor (terror, aterrorizar), ou seja, tem a ver com dominação (jurídicopolítica) da terra e com a inspiração do terror, do medo - especialmente para aqueles que, com esta dominação, ficam alijados da terra, ou no "territorium" são impedidos de entrar. Ao mesmo tempo, por extensão, podemos dizer que, para aqueles que têm o privilégio de usufruí-lo, o território inspira a identificação (positiva) e a efetiva "apropriação" (HAESBAERT, 2004, p. 94).
\end{abstract}

Na mesma linha de raciocínio, a partir da dupla conotação, material e simbólica, citada por Haesbaert (2004), Costa e Carvalho entende território como:

[...] contexto de relações sociais que se expressam em regras de uso (instituições) das disponibilidades naturais (biomas e ecossistemas) e culturais (capacidades difusas internalizadas nas pessoas e aparatos infraestruturais tangíveis e intangíveis) de um dado espaço geográfico politicamente delimitado (COSTA; CARVALHO, 2012, p. 115).

Vê-se que a proposta acadêmica de investigar sobre novos letramentos e novas tecnologias deve levar em consideração, em seus procedimentos metodológicos e na sua operacionalização, o que já é uma ortodoxia da teoria: a noção de que as práticas de letramento ocorrem de modo situado. Se há uma tendência de se pensar os contextos urbanos quase como se fossem esferas desterritorializadas, ou seja, como se, de fato, algumas propostas e considerações teóricas fossem universais ou independentes de um local de produção específico, esse elemento territorial é central nos contextos vinculados ao campesinato. Conforme defende Fernandes:

\begin{abstract}
Ao perder a propriedade, seu espaço de vida, seu sítio, sua terra e território, a família camponesa é desterritorializada. Como reação a esse processo, ocorrem a luta pela terra e as ocupações, na tentativa de criação e recriação da condição camponesa: campesinato e território são indissociáveis, e a separação entre eles pode significar a destruição de ambos (FERNANDES, 2012, p. 747).
\end{abstract}

Outro ponto que merece atenção é a ideia de tecnologia que sustenta a presente perspectiva. $\mathrm{O}$ uso das tecnologias aqui em foco não é compreendido a partir de uma visão evolucionista, no sentido de que sempre existirá uma tecnologia (ou técnica, ou metodologia) de ponta, a qual estará mais apta a resolver problemas de educação e 
linguagem, independentemente de onde eles ocorram. Ou seja, a tecnologia da escrita não é vista aqui como inferior à digital apenas porque a emergência daquela precedeu a desta última em termos temporais. Esse pressuposto é importante para colocar ênfase na pertinência contextual de certas tecnologias, a partir de um olhar que leve em conta o território em análise, mais do que no anseio por trazer para a discussão o que há de mais recente no mundo tecnológico.

Defende-se, portanto, que existe uma quantidade diversa de tecnologias, cujo uso dependerá de uma reflexão a respeito de como cada uma é ou não acessível e, além disso, podem ou não ser úteis nas práticas de linguagem comuns àquele território em particular. A prática docente cotidiana no curso de Licenciatura em Educação do Campo tem evidenciado situações em que a oralidade e a tecnologia de difusão via rádio podem, por exemplo, ter mais alcance do que tecnologias que precisem fazer uso de banda larga ${ }^{6}$.

Ressalta-se, ainda, que há uma urgência de o campo poder ocupar mais os espaços sociais de fala. Não que as práticas não existam. Mas, dentro da esfera acadêmica, elas ainda circulam muito pouco e são pouco legitimados. E, mesmo quando ocorre de terem maior visibilidade, em geral, isso ocorre a partir dos olhos de sujeitos e procedimentos vinculados à lógica urbana. Como exemplo disso, aliás, ressalta-se inclusive que os olhares aqui apresentados são de docentes e pesquisadores que, por razões diversas, entraram profissionalmente em contato com tal temática, a qual vivem a partir de um olhar institucional. São produções de certo modo híbridas: nem totalmente localizadas em territórios campesinos nem produzidas somente por pessoas que se identificam como camponesas, envolvendo professores acadêmicos com trajetórias urbanas e o modo

\footnotetext{
${ }^{6}$ Muitas das práticas de ensino vinculadas ao curso, por exemplo, ocorrem em comunidades em que não há acesso fácil a banda larga. Assim, as atividades pedagógicas de tais unidades curriculares, ao serem previstas pelos professores, não podem pressupor tal uso. Em contrapartida, em muitos desses contextos, lideranças locais se disponibilizam em produzir atividades em parceria e, não raro, ocupam local de destaque em tais espaços. No âmbito do curso, o projeto de extensão "Comunidades do Campo", do prof. Dr. Diogo Neves Pereira, seria um exemplo interessante de como essas tecnologias operam de forma híbrida. Os estudantes participantes do projeto coletam dados e fazem gravações via telefones celulares e, com a parceria da rádio universitária, conseguem disponibilizar os programas resultantes não só em podcast, mas também via rádio. Essa opção faz com que o programa atinja um público mais abrangente de contextos rurais nos quais a presença do rádio permanece bastante comum. Para saber mais sobre o projeto, é possível acessar o site: https://www.comunidadesdocampo.com.br Acesso em: 15 jun. 2019.
} 


\section{Dossiê Especial FICLLA}

REVISTA X, Curitiba, volume 14, n.5,p. 56-81, 2019

instituído de se fazer ciência nas universidades que reproduz, em certa medida, o que vem dos grandes centros urbanos. Porém, são atividades que envolvem sujeitos de realidades do campo e buscam fomentar seu protagonismo em um processo que é, ao mesmo tempo educativo, mas também vinculado a cadeias dialógicas concretas, fomentando a produção e veiculação de textos reais com autoria de sujeitos que, na maior parte, permanecem vivendo em realidades não urbanas ou pouco urbanizadas. Diante disso, contribuir para visibilizar tais questões pode ser uma forma de procurar fomentar essa realidade.

Os percursos reflexivos apresentados a seguir colocam em destaque vivências empíricas da atuação profissional dos autores do presente texto, dentro de nosso escopo de observação, que ainda é muito pequeno diante das diversas realidades existentes. No entanto, já se consegue perceber a quantidade de comunidades e de modos diversos de se construir uma vida e produzir sentidos podem coexistir - o que, por sua vez, demanda tecnologias e práticas específicas.

As próximas páginas são dedicadas a ilustrar essas necessidades inicialmente apontadas a partir da análise de realidades vinculadas à área de abrangência e atuação da LEC-UFVJM. Cada um dos cenários a serem apresentados nas próximas seções, em comum, permitem uma reflexão mais ampla sobre a importância de se considerar, nos debates sobre tecnologias e letramentos, a dimensão do território. Entende-se a importância dessa dimensão, em especial, quando o recorte de análise privilegia algumas entre muitas, complexas e diversas realidades campesinas, suas relações com questões de letramento, tecnologia e educação. Entende-se, também, que o território importa como local que, em alguma medida, marca as produções simbólicas locais concretizadas e tornadas públicas.

\section{EXPERIÊNCIAS EM LEITURA E ESCRITA NA UFVJM}

A comunidade discente da UFVJM é ampla e variada. Além de contar com estudantes que vêm de todo os cantos do país via Sistema de Seleção Unificada (SISU) que conta com as notas do Exame Nacional do Ensino Médio (ENEM) - há diversos estudantes residentes do norte e noroeste do estado e dos Vales do Jequitinhonha e Mucuri, locais de seus quatro campi; bem como outros tantos oriundos de regiões atendidas pela Educação à Distância $(\mathrm{EaD})$ e pela LEC. A LEC, curso que nos serve de exemplo para as 
reflexões sobre as práticas de letramento nesta seção, é uma graduação presencial cujo calendário alterna momentos na universidade e momentos nas comunidades dos estudantes, no que chamamos regime de alternância. A metodologia permite que os estudantes estejam em suas comunidades em momentos cruciais - como em época de colheita, em alguns casos - e na universidade o tempo necessário à sua formação; bem como promove um diálogo entre saberes, envolvendo comunidades e universidade na medida em que não só atividades de pesquisas protagonizadas por estudantes são realizadas em conjunto com suas comunidades de origem ou atuação profissional, como também é parte constitutiva do curso a ida periódica de docentes da universidade para orientação e execução de práticas de ensino, normalmente originárias de problematizações locais. O tempo em que estão na universidade chamamos de Tempo Universidade (TU) e acontecem de janeiro a fevereiro e de junho a agosto. O Tempo Comunidade (TC) ocorrem ao fim do Tempo Universidade, e é quando as comunidades recebem duas visitas de professores. Os períodos de férias, por sua vez, dão-se em junho e dezembro.

A LEC forma professores em duas habilitações interdisciplinares: Linguagens e Códigos e Ciências da Natureza. O trabalho docente no contexto do campo não tem grande apoio institucional no que diz respeito às suas especificidades, apesar da existência de cursos como o nosso. No entanto, a lógica do campo e de como esses territórios são constituídos colabora para um trabalho em certa medida contextualizado, tendo em vista que o(a) professor(a) percebe mais os seus estudantes e suas necessidades. Em uma comunidade rural, ou distrito, ou mesmo pequeno município, o(a) professor(a), quando vive na localidade, divide o convívio social com as famílias dos seus estudantes e, não raro, são até parentes. Assim, a relação que esse(a) professor(a) terá com sua comunidade será de maior aproximação, de maior conhecimento das práticas locais, como as letradas que aqui nos interessa prioritariamente, e das tecnologias nelas envolvidas. Invariavelmente, esse componente cultural, ligado às questões territoriais simbólicas e materiais, terá consequências nos processos educativos locais. No entanto, essas vozes são silenciadas em um espectro mais amplo e não são contempladas em políticas de estado que haveriam de ser mais democráticas. O Programa Nacional do Livro Didático (PNLD), por exemplo, tem 
apenas duas coleções voltadas para a educação do campo neste momento, sendo que as duas são destinadas a estudantes do primeiro ao quinto ano.

Diante da invisibilização que se presencia, conhecer mais profundamente tais territórios e sujeitos é parte dos esforços que devemos empenhar por uma educação mais equânime. Isso dialoga diretamente com os pressupostos levantados nas reflexões iniciais e está alinhado com uma visão que entende que diferentes práticas letradas emergem em diferentes contextos. Além disso, essa reflexão incide sobre, pelo menos, duas situações sobrepostas: o processo formativo desses licenciandos, que trabalharão, muitas vezes, em contextos nos quais a presença e a forma de se usar novas mídias e tecnologias se distancia do que consta em livros teóricos; e, também, a relação entre as demandas universitárias e as práticas e trajetórias de letramentos dos graduandos antes de seu ingresso no contexto acadêmico.

Dado o que foi apresentado ao longo do presente texto, há um risco de a realidade de tais ingressantes em relação a práticas e usos de linguagens e tecnologias ser invisibilizada, caso se perca a dimensão da distância entre tais cotidianos e formulações teóricas sobre o tema que partiram de outros territórios e contextos de produção. Essa invisibilização da variabilidade das relações e práticas que diversos sujeitos e comunidades podem ter em relação às linguagens e novas tecnologias é um ponto. Além disso, a própria dinâmica da graduação é, muitas vezes, pautada por necessidade de usos de tecnologias que são tidas como pressupostas. A universidade demanda que o estudante entenda, por exemplo, marcações de revisão em arquivo de texto digital, normas de apresentação de trabalhos acadêmicos, dentre outros - condições que, uma vez não cumpridas, podem impedir a permanência de tal estudante no contexto acadêmico. Promover uma educação mais igualitária, diante disso, é buscar oportunizar, dentre todo tipo de letramentos, aqueles que têm ou possam vir a ter uma inserção concreta em práticas cotidianas.

Nesse sentido, é de primordial importância, em vez de assumir como algo dado, perceber que o entendimento dos territórios e das realidades de um sujeito envolvido em uma prática educativa deve ser objeto de atenção para aplicação de atividades pedagógicas. Isso, quando se trata de atividades da área da linguagem, a partir também dos letramentos percebidos como presentes e dos entendidos como necessários em um diálogo com o local, 
mas em expansão para questões mais globais. Partindo dessas premissas, trazemos aqui três exemplos de atividades aplicadas nas nossas duas habilitações, mas sobretudo em Linguagens e Códigos.

A primeira delas refere-se a um trabalho que buscou promover uma reflexão teoricamente embasada sobre as práticas de letramentos dos próprios estudantes, para que entendessem os processos sociais de construção de sentidos pelos quais passaram, bem como as relações de tais processos com diversos gêneros textuais socialmente estabelecidos, diferentemente organizados de acordo com as especificidades contextuais. Referimo-nos a experiências da disciplina 'Gêneros Discursivos e Textuais (GDT)', de caráter obrigatório na habilitação Linguagens e Códigos, ofertada em 2016. A sequência de atividades propostas foi: (1) estudos teóricos sobre letramentos; (2) produção de texto autobiográfico sobre as relações dos estudantes com a leitura e a escrita; (3) revisão do material produzido pelos próprios estudantes com o uso de um editor de textos e outras ferramentas digitais como dicionários e buscadores eletrônicos; (4) revisão do material produzido pelo professor e impressão; (5) oficina de encadernação de livros; (6) escrita de artigo acadêmico para apresentação em congresso; (7) participação em congresso acadêmico nacional on-line com apresentação do artigo produzido. A busca foi por um processo focado não somente no aprendizado de novos gêneros, mas também no aprender a aprender sobre novos gêneros; a aprender a 'letrar-se' em novos gêneros.

A produção do livro, itens 2 a 5, atendeu ao propósito de fazê-los rememorar suas experiências e entender como se deram e se dão seus próprios processos de letramento, bem como as tecnologias neles envolvidas. Na sequência, os estudantes materializaram essas reflexões de ordem mais prática articuladas às outras de ordem teórica promovidas por leituras em artigos acadêmicos, conforme itens 6 e 7. No conjunto das atividades, foram demandados variados usos da língua: mais informais, como os relatos narrativos; e mais formais, como a edição dos textos narrativos, a produção do artigo acadêmico e sua apresentação em congresso. Dentre os temas debatidos, a partir da perspectiva dos letramentos, encontramos: ensino de língua portuguesa e atividades para letramentos em gêneros diversos; livros didáticos; experiências de letramentos com moradores do campo; vivências em ocupação e assentamento; participação de familiares nos letramentos de 
crianças; o Programa Institucional de Bolsa de Iniciação à Docência (PIBID); o ensino da gramática normativa de forma contextualizada em escolas rurais em regime de alternância; dentre outros.

A variedade de olhares e contextos no estudo dos mesmos temas é muito rica e, por conseguinte, produtiva. Por outro lado, a experiência prática de produção de um produto cultural que circula em esferas reais de interação, como a produção do livro e a participação no congresso, mobiliza diversos letramentos - alguns, inclusive, não previstos. Nesse processo, partiu-se da expectativa, por exemplo, que os sujeitos envolvidos conhecessem ferramentas de revisão, algo que não era a realidade de todo mundo. Se, em certos casos, isso se confirma, muitas vezes, ainda, há falta de infraestrutura adequada para garantir acesso a uma conexão de internet de qualidade razoável nas comunidades. É comum termos estudantes que acessam os ambientes virtuais de aprendizagem apenas pela rede celular, o que, em muitas situações, é um impeditivo para abrir um arquivo maior ou rodar um vídeo. Em contextos assim, não surpreende que práticas com texto desconsiderem, por exemplo, o uso de corretores ortográficos e editores de texto on-line. Muitos estudantes, assim, começam a usar tais ferramentas apenas no contexto da universidade.

A prática de produção dos livros promoveu uma aproximação com o uso de ferramentas digitais diversas para o trato com o texto, além do contato com um objeto de valor simbólico que importa na contextualização e na construção de significados envolvidos em todo o processo de aprendizagem: um livro de autoria própria, mesmo que inicialmente construído de modo artesanal. O material foi produzido, revisado e editado digitalmente por meio dos editores de texto a que o estudante tinha acesso, normalmente o Microsoft Word ou o Writer. Trabalhamos com as ferramentas de revisão, produzimos um único arquivo com todos os escritos memorialísticos, imprimimos em impressora comum no formato livreto e promovemos uma oficina de encadernação de livros com o uso de linha grossa para tricô ou barbante e furadores de papel. O processo envolveu, ainda, a produção da capa e a escolha do título, o que aconteceu com a participação de todos. A experiência foi repetida e expandida, como veremos mais adiante.

A segunda experiência da LEC-UFVJM que aqui trazemos refere-se à disciplina Leitura e Produção de Textos (LPT) ofertada em 2017 para estudantes de terceiro período 
das duas habilitações. Dessa experiência, tivemos dois produtos: um dossiê sobre educação e outro livro artesanal, mas agora com versão digital pela editora da universidade. $\mathrm{O}$ tema do dossiê foi escolhido pela turma. Contou a favor da escolha a importância de se discutir o contexto político para a educação naquele momento, que envolvia tanto a aprovação da Medida Provisória (MP) 746/2016 - a qual alterou o Ensino Médio sem debate público como também a Proposta de Emenda Constitucional (PEC) 55/2016, que congelou os gastos públicos na esfera federal por 20 anos. Contra as reformas, houve um movimento grande de resistência por parte de docentes e técnicos de educação de diversas instituições que entraram em greve Brasil afora; de estudantes secundaristas e universitários que ocuparam escolas e universidades por vários dias com aulões e outras atividades; manifestação popular em Brasília; dentre outros desdobramentos que acabaram por não reverter o quadro. Vale ressaltar que, a greve em questão, da qual a universidade participou, afetou diretamente os estudantes naquele momento.

Enfatizamos que em janeiro de 2017, os estudantes da LEC-UFVJM chegavam à Diamantina um tanto distantes de toda a discussão relatada no parágrafo anterior, pois o diálogo com a universidade no TC se restringiu ao necessário para a confecção dos trabalhos e execução das práticas. Nas comunidades, por sua vez, os debates não chegavam com a mesma força e o mesmo detalhamento que era comum a quem estava com maior acesso às grandes mídias e ao meio digital. O dossiê produzido, a fim de abranger o maior número de questões e pontos de vista, foi um trabalho coletivo que envolveu professores, estudantes, a comunidade acadêmica e não acadêmica da cidade de Diamantina, as quais contribuíram com entrevistas e informações. Diferentes grupos de estudantes pesquisaram diferentes perspectivas sobre a greve de 2016 e produziram dez textos diferentes que, além de apresentação e considerações finais, trataram de: ocupações dos estudantes na UFVJM e nas escolas de Diamantina; a participação do movimento estudantil; a luta das escolas do campo; o comando de greve; a greve e a LEC; manifestação Nacional em Brasília; a perspectiva dos comerciantes locais; conjuntura política nacional e internacional.

A fim de dar um propósito funcional para a atividade, inserindo nossos estudantes em práticas letradas reais, foi decidido em conjunto e antecipadamente que o material seria publicado em um repositório de objetos educacionais denominado <sementeia.org>, 


\section{Dossiê Especial FICLLA}

REVISTA X, Curitiba, volume 14, n.5,p. 56-81, 2019

mantido pela UNICAMP, onde os links apontados no parágrafo anterior podem ser conferidos. Nesses trabalhos e reflexões sobre letramentos, é interessante apontar as surpresas que temos pelo caminho, pois apesar de estes professores pesquisadores serem da Linguística Aplicada e a contextualização, assim, não ser uma novidade, as questões simbólicas que envolvem o grupo particularmente envolvido são extremamente novas e de grande relevância para o processo educativo. Notamos que todo o processo de produção do dossiê contribuiu para a assimilação das informações que, até então, chegavam muito difusas; para o domínio das técnicas necessárias à produção de textos digitais; além da aprendizagem de certas normas/técnicas específicas do contexto acadêmico como normas ABNT, linguagem científica, etc. Ao longo do processo de pesquisa e produção, gêneros acadêmicos como esquemas, fichamentos e resumos também foram exploradas em práticas sociais relevantes ao trabalho em desenvolvimento.

Tal como a experiência da disciplina GDT, o segundo produto de LPT foi o livro artesanal. Desde o início, já pensávamos em um lançamento oficial em editora, mesmo que em e-book, quando da soma de novos textos ao nosso material. A oportunidade de completar 68 textos veio com essa disciplina, LPT, ofertada em 2017, onde refletir sobre os processos de leitura e escrita também era relevante. Em novembro de 2017, o e-book Memórias de Letramento foi lançado pela Editora UFVJM. A capa de um dos nossos livros artesanais encontra-se à esquerda e a capa do e-book, à direita, na Figura 1 a seguir.

Figura 1

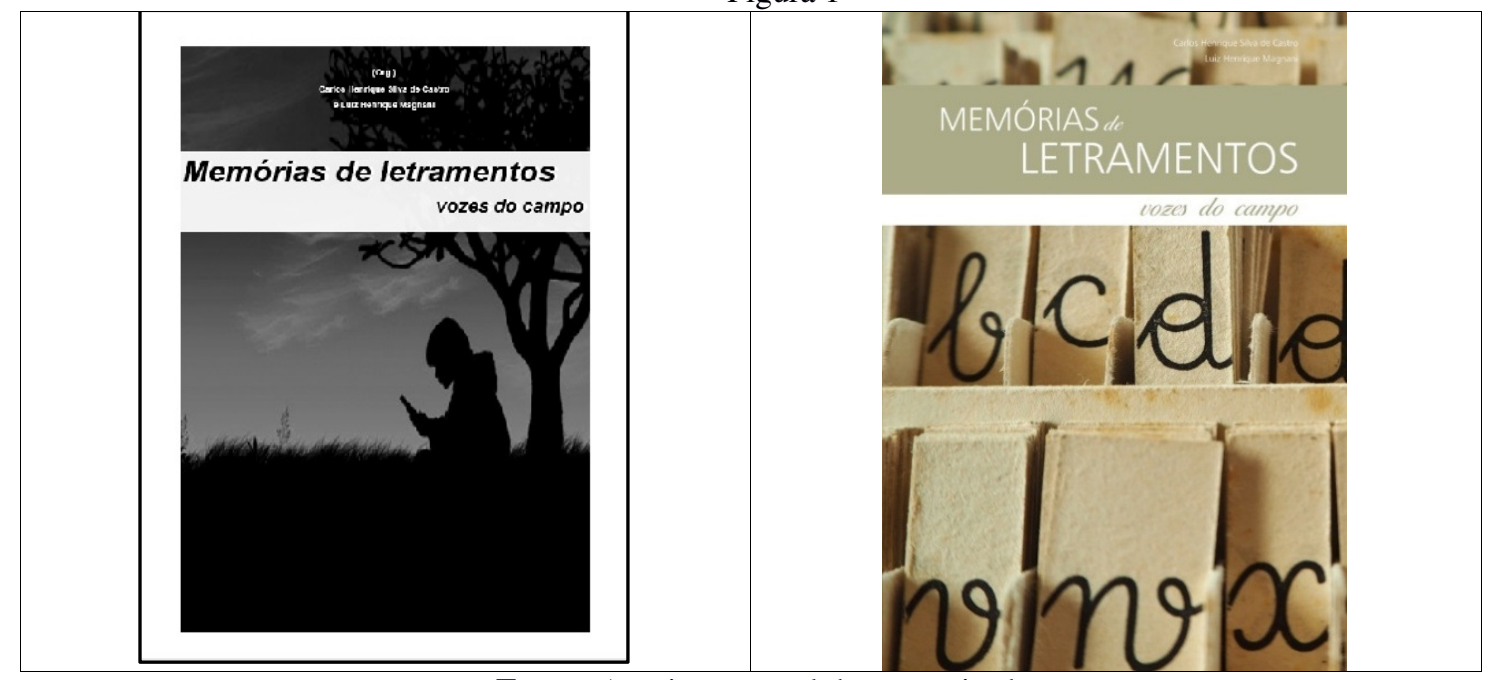

Fonte: Arquivo pessoal dos pesquisadores 


\section{Dossiê Especial FICLLA}

REVISTA X, Curitiba, volume 14, n. 5, p. 56-81, 2019

As reflexões sobre os processos, por sua vez, levam à autonomia e resultados não previstos podem surpreender. Os estudantes não foram orientados, por exemplo, a levarem a experiência de produção dos livros para seus estágios. No entanto, isso aconteceu em, pelo menos, duas comunidades. Em Ouro Verde de Minas, ao norte do estado, produziram poesias e fizeram seus livros artesanalmente. Os estudantes dos nossos estagiários foram fotografados com seus livros, como pode ser visto a seguir.

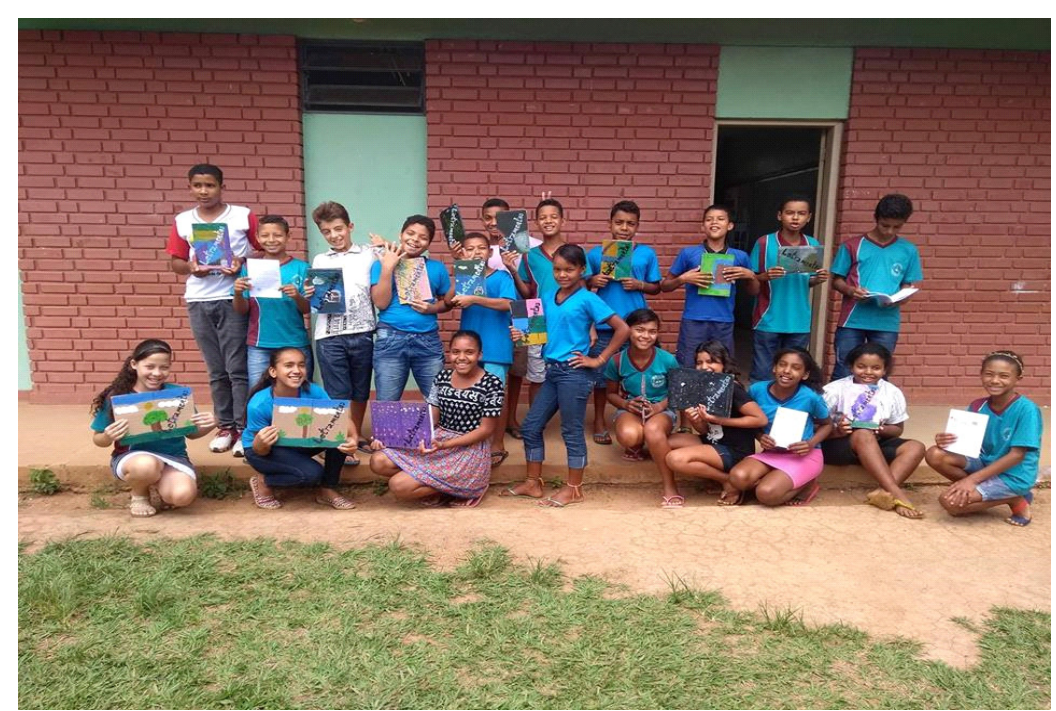

Fonte: Arquivo pessoal dos pesquisadores

O segundo caso aconteceu em uma escola em que promoveram o processo de produção textual em diversas turmas da educação básica, incluindo turmas de jovens e adultos, com gêneros textuais diferentes de acordo com o perfil de cada uma para, ao fim, produzirem seus livros artesanais, além do livro digital Padre João Afonso: traços e laços de uma comunidade do campo que também foi lançado pela Editora UFVJM.

Surpresas como as mencionadas devem ser vistas como um elemento com o qual o estudioso da Linguística Aplicada deve estar sempre apto a lidar, uma vez que entende que sua área é voltada ao uso da língua e da linguagem e, portanto, ao acontecimento - o que inclui o componente da imprevisibilidade em qualquer processo. No caso em questão, além disso, apontam para o desconhecimento prévio, da parte dos professores, em relação a diversos aspectos culturais que envolvem as comunidades e suas práticas sociais. Dessa 
forma, dar voz aos estudantes contribui, também, para um trabalho contextualizado de forma adequada, no qual o aprendizado é, de fato, mais horizontal e dialógico.

Em termos de pesquisa, a área Linguagens e Códigos, quando coloca foco nos usos da língua e da linguagem ainda têm assumido como objetos investigativos, em grande parte, fenômenos do contexto urbano. Assim, esse diálogo com outros saberes torna-se ainda mais relevante. Para o ensino mais democrático, a perspectiva da diversidade deve dividir o protagonismo das atenções com as perspectivas mais canônicas. O exemplo do livro de padre João Afonso, bem como os outros citados, não apenas contribui para a reflexão sobre o contato com os textos, mas para o letramento e a autonomia de estudantes que replicaram a experiência de acordo com as especificidades locais e produziram mais reflexões e mais letramentos. $\mathrm{O}$ que podem parecer tecnologias triviais para muitos, ao se partir de um olhar urbano e dos grandes centros legitimados na produção de conhecimento, no contexto do campo se mostraram com um potencial enorme para as práticas sociais dessas pessoas. Notamos, por exemplo, que o material produzido na escola do campo trouxe não apenas gêneros diferentes (como poemas, receitas, narrativas), mas ideias e técnicas diferentes das utilizadas por nós, os professores universitários, como a digitalização de desenhos feitos pelos estudantes à mão livre.

Uma outra atividade importante não apenas para as práticas de leitura e escrita dos estudantes, mas também para o letramento crítico de suas comunidades, na medida em que noticia eventos e projetos das comunidades e dá voz a seus sujeitos, foi um projeto de ensino intitulado Práticas de Letramento e Comunicação Comunitária: um instrumento de aperfeiçoamento da capacidade de leitura e produção de texto para o curso de graduação em educação do campo, do Programa de Apoio ao Ensino de Graduação (PROAE). O projeto, em suma, destinava-se a produzir gêneros jornalísticos sobre as comunidades dos estudantes. Para isso, foram organizadas oficinas de comunicação comunitária para os participantes do projeto que eram, então, cinco bolsistas sob a orientação de cinco professores diferentes. No entanto, até mesmo por falta de verba para produzir material impresso, toda produção foi publicada apenas on-line em uma fanpage do Facebook. $\mathrm{O}$ projeto foi finalizado no segundo semestre de 2016, quando do fim dos recursos e do prazo do edital que o originou. 


\section{Dossiê Especial FICLLA}

REVISTA X, Curitiba, volume 14, n.5,p.56-81, 2019

Em 2018, o projeto foi retomado a partir de edital também do PROAE com o nome Olhares do Campo. Com duração inicial de um ano, mas já renovado para igual período, o projeto propõe-se a ser um laboratório de comunicação comunitária, trazendo foco nos processos educativos, bem como no uso das tecnologias envolvidas. Com apenas um bolsista inicialmente, o projeto, na segunda versão, contou com dois bolsistas e alguns estudantes voluntários, que se ocuparam da escrita e edição, e professores que coordenam e orientam as revisões e edições. O grupo mantém uma rotina de publicação semanal em site próprio e em uma fanpage no Facebook e, bimestralmente, as principais notícias são sintetizadas em um boletim que é enviado para o canal de notícias da LEC-UFVJM, bem como para as escolas do campo da região a fim de que o exponham em espaço público. Nesse processo educativo, o estudante entra em contatos com diferentes gêneros textuais socialmente relevantes, aprende a lidar com esses gêneros em termos de forma e estilo, mas sobretudo de conteúdo, o que potencialmente expande a leitura de mundo e o entendimento das complexidades por parte do sujeitos, e proporciona práticas diversas com o digital para a leitura e a produção e textos, a exemplo de habilidades citadas como edição, leitura de interfaces, gramática normativa, normas de formatação, dentre outros.

\section{CONSIDERAÇÕES FINAIS}

O que se percebe, ao longo de todos os processos relatados na seção anterior, é que o perfil médio dos estudantes em foco não teve acesso a muitas das tecnologias atualmente mais difundidas a certos nichos do contexto urbano normalmente priorizados em estudos sobre o tema. Porém, logo que tais tecnologias começam a fazer parte de suas práticas sociais correntes, os aprendizados acontecem e muitas práticas letradas passam a fazer sentido e, com isso, inserem-se em redes das quais os atores já faziam parte. Outras tecnologias, em seu turno, não precisam necessariamente ser buscadas como salvadoras dos letramentos locais na medida que as tecnologias são importantes apenas quando são parte das realizações textuais dos sujeitos locais, quando fazem parte das práticas sociais desses sujeitos. E isso pode mudar facilmente de acordo com os contextos. Certos estilos de vida podem, por exemplo, prescindir do uso da internet. O que nem sempre é o caso de 


\section{Dossiê Especial FICLLA}

REVISTA X, Curitiba, volume 14, n.5,p. 56-81, 2019

professores do século XXI que convivem em um contexto de globalização propiciado, em grande medida, pelo acesso e uso do meio digital.

Nesse sentido, torna-se um desafio - tanto na vida de tais sujeitos quando em termos de políticas públicas relacionadas à educação e democratização de conhecimentos - o fato, por exemplo, de que muitos licenciandos retornam para suas comunidades e continuam sem banda larga. Certas práticas letradas vivenciadas no contexto universitário podem deixar de fazer parte de sua realidade e, assim, um diálogo mais abrangente para além das questões locais pode ser comprometido. Mas, para além dessas e outras questões políticas, o professor deve se esforçar para perceber que práticas letradas são significativas nos contextos dos seus alunos sem, no entanto, deixar de promover o diálogo do local com o global tendo em vista a realidade híbrida em que vivemos, mencionada na primeira parte desse trabalho. Garantir acesso e equidade é uma tarefa destinada a todos e na qual, certamente, os menos providos de recursos e possibilidades mais se empenham.

Em resposta a esse cenário, defende-se que há um deslocamento que urge se consolidar no contexto acadêmico, particularmente no caso do presente recorte, no âmbito dos estudos sobre linguagem, letramento e tecnologias. Esse deslocamento consiste em considerar o fator territorialidade como relevante como parte das reflexões vinculadas ao tema e, cada vez mais, o campo como território válido e importante de produção de conhecimento, ponto de partida para reflexões teóricas, cujos viveres importam nas reflexões e no debate público mais amplo a respeito das práticas de letramento, usos de tecnologia e construção de sentido. Na condição de professores universitários que atuam com formação docente, tais reflexões também podem nos ajudar a pensar práticas acadêmicas ligadas a esses usos de tecnologias que podem nos ajudar a propiciar letramentos em contextos de ensino, Mais que isso, na prática, estudantes estão sendo sistematicamente incentivados a divulgarem resultados de suas próprias reflexões sobre o tema na academia dentro de unidades curriculares do curso, resultando em publicações ${ }^{7}$.

\footnotetext{
7 Ver, por exemplo, Santos (2016). Além disso, o próprio exemplo trazido do projeto de extensão Comunidades do Campo pode ilustrar como esse processo pode gerar reflexões envolvendo participantes do projeto. A esse respeito, ver Pereira e Mendes (2019).
} 


\section{Dossiê Especial FICLLA}

REVISTA X, Curitiba, volume 14, n.5,p. 56-81, 2019

Esse componente territorial, aliás, é relevante de ser levado em conta tanto em processos de pesquisa como também nas propostas educacionais desenvolvidas para as escolas e demais instituições educativas de tais regiões. Essa necessidade fica evidente em um contexto como o da institucionalização da Educação do Campo nas universidades federais brasileiras, o qual acabou e continua por colocar, muitas vezes, aspectos cotidianos das diversas realidades campesinas em pauta, em grande parte das vezes, por acadêmicos que tiveram uma trajetória formativa que desconsiderou esse tipo de discussão (MAGNANI; CASTRO; MARQUES, 2018).

Os exemplos trazidos para reflexão não esgotam a diversidade de realidades nas quais a reflexão sobre tecnologias e letramento podem ocorrer, sejam contextos nãourbanos ou menos urbanizados. Em vez disso, procuram justamente apontar para a complexidade da questão, bem como para a necessidade de investigações mais aprofundadas a respeito de diferenças de uso e assimetrias de acesso a tecnologias nas realidades que vão para além dos centros urbanos. Além disso, levantam uma demanda por uma quantidade maior de estudos que se aprofundem nos aspectos aqui apresentados, os quais podem dar maior detalhamento de particularidades de outras práticas letradas, nem sempre em foco, investigando, a partir disso, conflitos, diferenças, similaridades e outras características dessas práticas. E, por outro lado, servindo de material e registro para quem atua profissionalmente em locais similares.

Argumenta-se que tais atitudes, por sua vez, podem contribuir para a articulação global de lutas contra-hegemônicas (SANTOS, 2005; 2018), bem como para a visibilização de atores e práticas sociais e usos de tecnologias que, por vezes, ainda se localizam fora do escopo de atenção de muitos acadêmicos.

\section{REFERÊNCIAS}

ARAÚJO, J; LEFFA, V. Redes sociais e ensino de línguas: o que temos de aprender? São Paulo: Parábola Editorial, 2016.

BRAGA, D. B. Ambientes Digitais: Reflexões Teóricas e Práticas. São Paulo: Cortez, 2013. 
BRAGA, D. B. Tecnologias Digitais da Informação e Comunicação e Participação Social: possibilidades e contradições. São Paulo: Cortez, 2015.

BUZATO, M. E. K. Entre a Fronteira e a Periferia: linguagem e letramento na inclusão digital. 2007. 284 f. Tese (Doutorado) - UNICAMP, Campinas, 2007.

CASTRO, C. H. S.; MAGNANI, L. H. Memórias de letramentos:vozes do campo. Editora UFVJM: Diamantina, 2017.

COSTA, F, A; CARVALHO, H. M. Campesinato. In: CALDART, R. S; PEREIRA, I. B.; ALENTEJANO, P.; FRIGOTTO, G. Dicionário da Educação do Campo. Rio de Janeiro/São Paulo: Escola Politécnica de Saúde Joaquim Venâncio, Expressão Popular, 2012.

GEE, J. P. What Video Games Have to Teach Us About Learning and Literacy. New York: Palgrave/Macmillan, 2003.

FERNANDES, B. M. Território Camponês. In: CALDART, R. S; PEREIRA, I. B.; ALENTEJANO, P.; FRIGOTTO, G. Dicionário da Educação do Campo. Rio de Janeiro/São Paulo: Escola Politécnica de Saúde Joaquim Venâncio, Expressão Popular, 2012.

FIORIN, J. L. Aula Inaugural de Linguística. Aula inaugural do Bacharelado em Linguística da Universidade de São Carlos de 2012. São Paulo: UFSCar, 2012. Acesso em 30 de maio de 2019. Disponível em: https://www.youtube.com/watch?v=hI17FcRY2Ec. Acesso em: 15 jun. 2019.

HAESBAERT, R. $O$ mito da desterritorialização: do fim dos territórios à multiterritorialidade. Rio de Janeiro: Bertrand Brasil, 2004.

HUNG, C. Making sense of video games: an ethnographic case study on the meaningmaking practices of Asian adolescents. 191f. Tese (Doutorado em Educação). Teachers College, Columbia University, New York, 2009.

JENKINS, H. Cultura de convergência. São Paulo: Aleph, 2008.

JESUS. D. M.; MACIEL, R. F. Olhares Sobre Tecnologias Digitais: Linguagens, Ensino, Formação e Prática Docente. Campinas, SP: Pontes Editores, 2015.

KUHN, T. S. A estrutura das revoluções científicas. São Paulo: Perspectiva, 1975.

LEVY, P. Cibercultura, Rio de Janeiro: Editora 34, 1999.

MAGNANI, L. H.. Um passo para fora da sala de aula: novos letramentos, mídias e tecnologias. Revista X, v. 1, n. 1, p. 01-18, 2011. 
MAGNANI, L. H.; CASTRO, C. H. S.; MARQUES, L. O. C. Da política pública de educação do campo à prática acadêmica para a formação de professores. Revista Educação e Políticas em Debate, v. 7, n. 1, p. 58-76, jan./abr. 2018.

NUNES, J. A. Teoria crítica, cultura e ciência: $\mathrm{O}(\mathrm{s})$ espaço(s) e o(s) conhecimentos(s) da globalização. In: SANTOS, B. S. (Org.). A Globalização e as Ciências Sociais. São Paulo: Editora Cortez, p. 301-344, 2005.

PEREIRA, D. N.; MENDES, M. T. O uso de 'novas' tecnologias na educação básica: interdisciplinaridade e valorização cultural em escolas do campo. Revista EducVale. v. 1, n. 1, p. 29-45, 2019.

RAJAGOPALAN, K. Relevância Social da Linguística. In: RAJAGOPALAN, K. Por uma linguística crítica: linguagem, identidade e a questão ética. São Paulo: Parábola Editorial, p. 37-48, 2003.

SANTOS, B. S. Os processos de globalização. In: SANTOS, B. S. (org.) A Globalização e as Ciências Sociais. São Paulo: Editora Cortez, p. 25-102, 2005.

SANTOS, B. S. A filosofia à venda, a douta ignorância e a aposta de Pascal. Revista Crítica de Ciências Sociais, 80, p. 11-43, 2008.

SANTOS, B. S. End of the Cognitive Empire: The Coming of Age of Epistemologies of the South. Duke: University Press, 2018.

SANTOS, M. N. R. Letramento Digital em uma Comunidade do Campo. In: Congresso Nacional Universidade, EAD e Software Livre 2016/2, Belo Horizonte, Minas Gerais. Anais (on-line). Belo Horizonte-MG: UEADSL. v. 1. n. 7, 2016.

SIGNORINI, I. Do residual ao múltiplo e ao complexo: o objeto da pesquisa em Linguística Aplicada. In: SIGNORINI, I.; CAVALCANTI, M. C. (Org.). Linguística Aplicada e Transdisciplinaridade. Campinas: Mercado das Letras, p. 99-110, 1998.

TAKAKI, N. M.; MACIEL, R. Letramentos em Terra de Paulo Freire. Campinas: Pontes Editores, 3ed. (ampliada), 2017.

TAKAKI, N. H.; MONTE MÓR, W. Construções de sentido e letramento digital crítico na área de línguas/linguagens. Campinas: Pontes Editores, 2017.

TURKLE, S. Life on Screen. New York: Simon and Schuster, 1995.

ZACCHI, V. J. A enxada e a caneta: linguagem e cultura na construção da identidade do sem-terra. São Paulo: Humanitas, 2016. 
Dossiê Especial F ICLLA

REVISTA X, Curitiba, volume 14, n.5,p. 56-81, 2019

ZACCHI, V.; WIELEWICKI, V. H. G. Letramentos e Mídias: Música, Televisão e Jogos Digitais no Ensino de Língua e Literatura. Maceió: EDUFAL, 2015. 